\title{
Tecnomatix Plant Simulation, Its Features and Its Integration into Business Processes in Logistics Systems
}

\author{
Marek Kliment ${ }^{1, *}$, Peter Trebuňa ${ }^{1}$, Martin Straka \\ ${ }^{1}$ Department of Industrial engineering and management, Technical University of Košice, Faculty of Mechanical Engineering, Košice, \\ Slovakia \\ ${ }^{2}$ Logistics Institute of Industry and Transport, Faculty of mining, ecology, process control and geotechnology, Košice, Slovakia \\ *Corresponding author: peter.trebuna@tuke.sk
}

Received October 13, 2014; Revised October 31, 2014; Accepted November 12, 2014

\begin{abstract}
The aim of this paper is to bring the advantages of software module from Tecnomatix portfolio. It deals with Plant Simulation software module, its characteristics and subsequent integration into established business processes. The software will be integrated into process of storage and logistics chain in manufacturing plant.
\end{abstract}

Keywords: simulation, model, storage, sorter

Cite This Article: Marek Kliment, Peter Trebuňa, and Martin Straka, "Tecnomatix Plant Simulation, Its Features and Its Integration into Business Processes in Logistics Systems.” American Journal of Mechanical Engineering, vol. 2, no. 7 (2014): 286-289. doi: 10.12691/ajme-2-7-24.

\section{Introduction}

The trend at the moment, but also over the past decades are Information Technologies. Through these technologies companies nowadays govern their production, as well as administrative processes. Without them, existence of even one enterprise was today not possible, whether large or small. In business practice several types of tools are used from ranks of information technologies. The most basic tools are for controlling administration. Among more complex are those which are already used to a partial or full management of production in certain positions, or entire production halls. Among the most complex we can include means to verify the process of planning future work practices. Planning and assessing future status of planned production by those means and subsequently they can be applied in the process of governance of real production.

\section{Plant Simulation, Characteristics and Advantages}

Plant Simulation is a computer software developed by Siemens PLM Software for modeling, simulation, analysis, visualization and optimization of production systems and processes, material flow and logistics operations [14]. Using Tecnomatix Plant Simulation enables users to optimize material flow, resources for all levels of planning. The software allows comparison of complex manufacturing production options, including immanent logic processing, using computer simulation. Plant Simulation is used for individual production plans as well as multinational enterprises, mainly as a strategic planning layout, process control logic and complex dimensions of productive investment. This is one of the main reasons for the dominance of this product on market.

Object-oriented programming uses the following three properties:

1. Heritage - Users create libraries with their own objects that can be re-used. Unlike copies, any change in the object class library is extended to some of the derived objects (children).

2. Polymorphism - Classes can be derived and derived method can be redefined. It allows users to create complex models faster, easier and more transparent in the structure.

3. Hierarchy - complex structures can be created very clear on several logical layers, allowing each layer to move between them by relevance.

The program can import data from other systems, such as. Program Access, Oracle databases, Excel or SAP.

Integration of Plant Simulation supports:

- Import data from PLM systems, or can be directly used,

- virtual enterprise putting into service

- download data from AutoCAD,

Microstation, FactoryCAD, etc. directly into the simulation.

It provides a clear analytical tools for detecting obstacles for monitoring material flow (Sankey diagram) or to detect over sized batteries (Chart).

Provides integrated optimization tools:

- Experiment Manager automatically creates scenarios and evaluate the dependence of two input parameters.

- Genetic algorithms search large space solution.

- Neural networks show the connection between input and output parameters and can be used for forecasting.

The program can: 
- Recognize and show problems that might otherwise result in high cost and time consuming remedial measures in the start-up phase.

- Offers mathematically calculated key performance indicators (KPI) instead of an expert,, feeling ".

- Reduce investment costs for production lines without jeopardizing the desired quantity.

- Optimize the performance of existing production lines.

- Incorporate machine failure, availability (MTTR, MTBF) when calculating the numbers throughput and usability.

Higher productivity planning, the program can be achieved by:

- Collection and management of knowledge within a single source of information will ensure the reuse of certified processes and cut costs for capital equipment.

- Ensuring and Troubleshooting in production systems that would otherwise require time-consuming and costly remedial measures at the onset of production.

- By limiting tasks associated with planning assembly, shortening, planning and reducing related costs.

- By sharing and analyzing information within the digital environment, offering a detailed overview of the various stages of the development process and the impact of these processes.

- Streamlining communications can quickly adapt to customer requirements, the decision is based on facts.

\section{Analysis of the Current Situation in Distribution of Products in the Company}

This is part of the enterprise, whose main task is to ensure stocking of put-away products and subsequent planned export. Enterprise ensures the production of selected models, or their modifications under orders that are processed as quickly as possible, no tere is no surplus stock on warehouse.

Enterprise implements requirements under two types of orders:

1. BTO - (bill to order) - they usually order one to three models, a certain amount.

2. RDC (Regional Distribution Centre) - stock for mostly logistics centers or end customers, that means more models.

The plant produces two types of products:

1. TOP LOADER - used to sort product type TOP (short T)

2. FRONT LOADER - used to sort product type FRONT (short F)

Manufactured, packaged and labeled products are transported on a conveyor belt to physical distribution, whose main task is to distinguish the product model and subsequently classify it.

Products are by input conveyor belt transported to elevator, which moves the two products to a sorter. In a sorter conveyor handler sets entry requirements, under which the device will sort input products within ten places associated conveyors, each of which has three elevators with capacity of five pieces on one such conveyor. If Sorter requires output to full destination, the entire belt system is blocked, until conveyors do not displace products. For each input are available two forklifts during the workday. Overall, one can pass twelve pieces of products taken by contact force from the side.

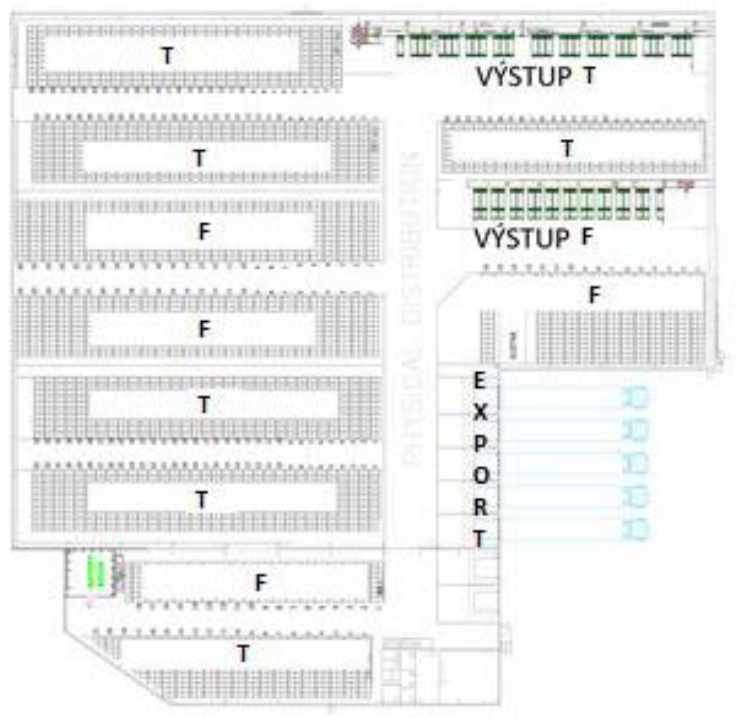

Figure 1. Warehouse layout

For products expedition four such trucks are available, whose main task is removing products under BTO or RDC orders.

Expedition is the last part of the process. There are four port ramps for loading products in tandem. For each ramp one forklift and one operator is available, whose main task is to scan products according to the order and stack them for more pieces, so as to ensure stability during transport. For each order is ordered a competent tandem to ensure that $\mathrm{i}$ tis filled up, respectivelyto provide the most efficient use. After preparing the tandem will dispatch the appropriate forklift weights required products according to the order to appropriate place where manipulator controls orders by scanning. After order control products are sequentially stacked. And loaded into parked tandem. Tandem shall be filled unless it fills the entire space, respectively unless the order is not completed.

\section{Application of Simulation Module in the Enterprise System}

Table 1. Designation and pieces of dailynet working shift after breaks deduction

\begin{tabular}{|c|c|c|}
\hline Typin reality & Typinprogramme & Pieces per day \\
\hline Front & A & 5270 \\
\hline Top & B & 3300 \\
\hline
\end{tabular}

Table 2. Product inputs table

\begin{tabular}{|c|c|c|c|c|c|}
\hline & object 1 & real 2 & integer 3 & string 4 & table 5 \\
\hline String & MU & Frequency & Number & Name & Attribures \\
\hline 1 & .Mus.Entity & 0.05 & & typ1 & \\
\hline 2 & .Mus.Entity & 0.07 & & typ2 & \\
\hline 3 & .Mus.Entity & 0.10 & & typ3 & \\
\hline 4 & .Mus.Entity & 0.12 & & typ4 & \\
\hline 5 & .Mus.Entity & 0.15 & & typ5 & \\
\hline 6 & .Mus.Entity & 0.17 & & typ6 & \\
\hline 7 & .Mus.Entity & 0.20 & & typ7 & \\
\hline 8 & .Mus.Entity & 0.22 & & typ8 & \\
\hline 9 & .Mus.Entity & 0.25 & & typ9 & \\
\hline 10 & .Mus.Entity & 0.27 & & typ10 & \\
\hline
\end{tabular}


For the purposes of the program will FRONT type referred as type A and TOP type as $\mathrm{B}$. These products were adjusted to daily production, which is for current status displayed in Table 1.

Products are generated as needed for BTO or RDC orders (Figure 2), we set the program to twenty-four hour shift production to 8570 units. To simplify the inputs we linked the table with the entry of products into the simulation (Table 2).

The real state of sorting by nine methods we moved into Plant Simulation environment (Figure 2).

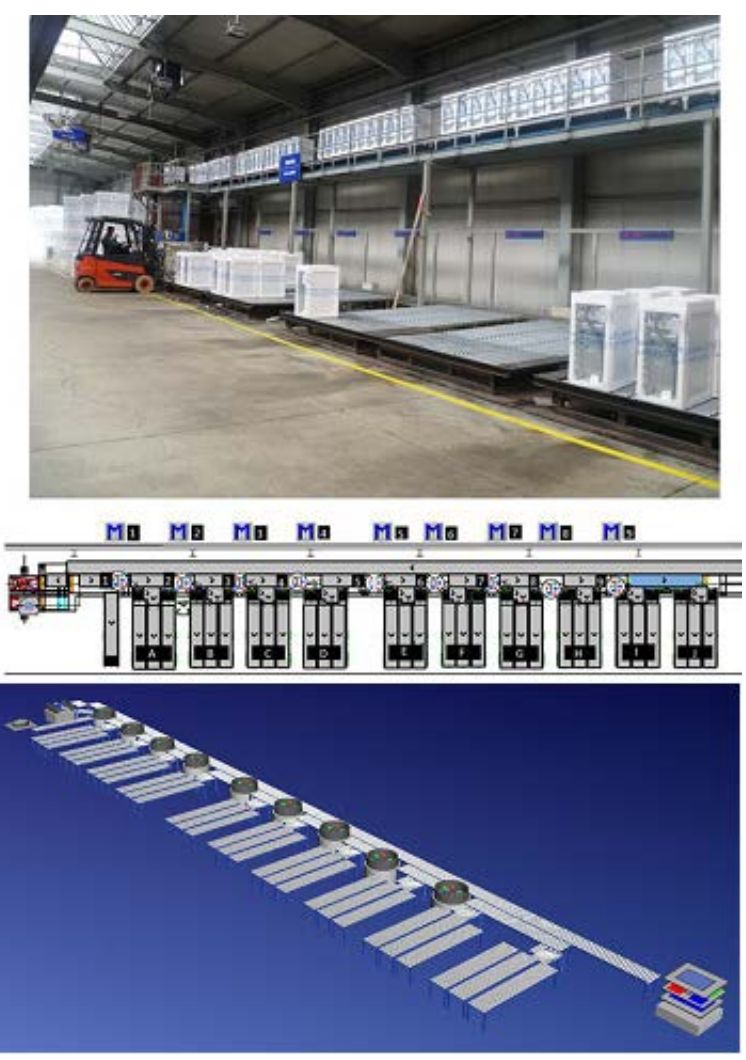

Figure 2. Sorting by nine methods moved into Plant Simulation environment (2D a 3D)
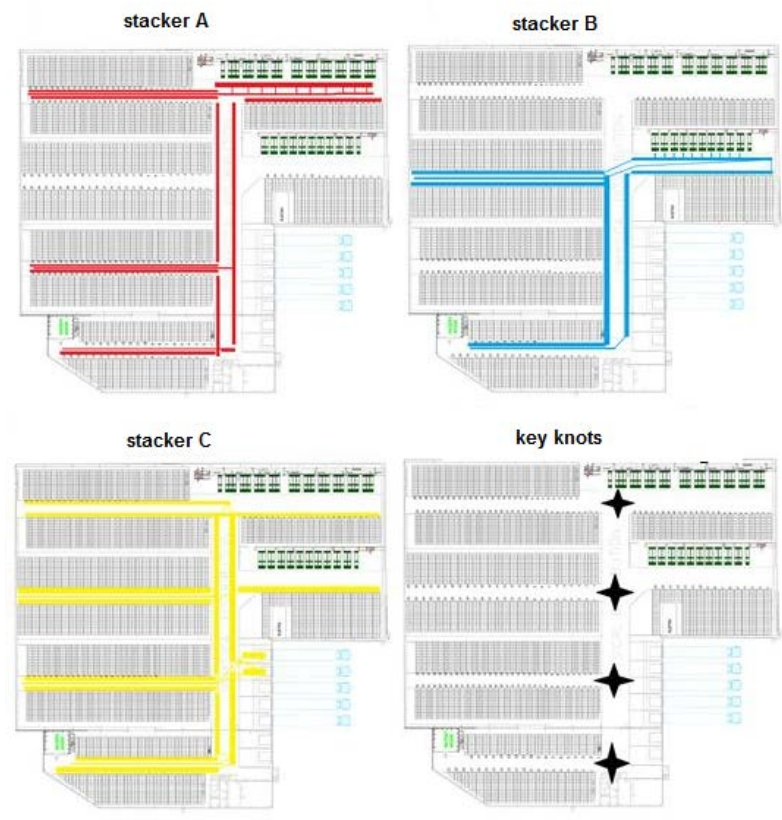

Figure 3. Truck movement after operation and identification of main nodes
In simulations we divided the real sorter into 9 methods, whose main task is to recognize the name of the entity and classify them on the basis of command in the method.

Products that are on the belts A, B,....J are operated by forklift, which controls one worker. Overall, two trucks operate on one Sorter. The carriage is movable unit in the object, whose main task is transfer of products from sorter to the warehouse for selected product model. In simulating traffic in the warehouse, we have trucks labeled A, B, C, color distinguished, each having a capacity of more than 12 pieces of products (Figure 4). Individual nodes had to be programmed so that the program worked smoothly.

\section{Storage Simulation}
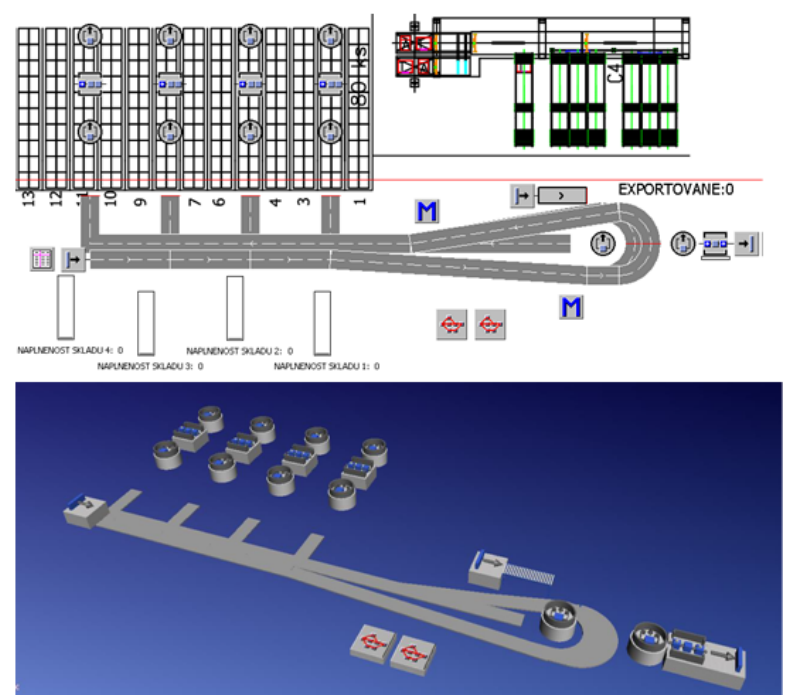

Figure 4. Storage and removal model
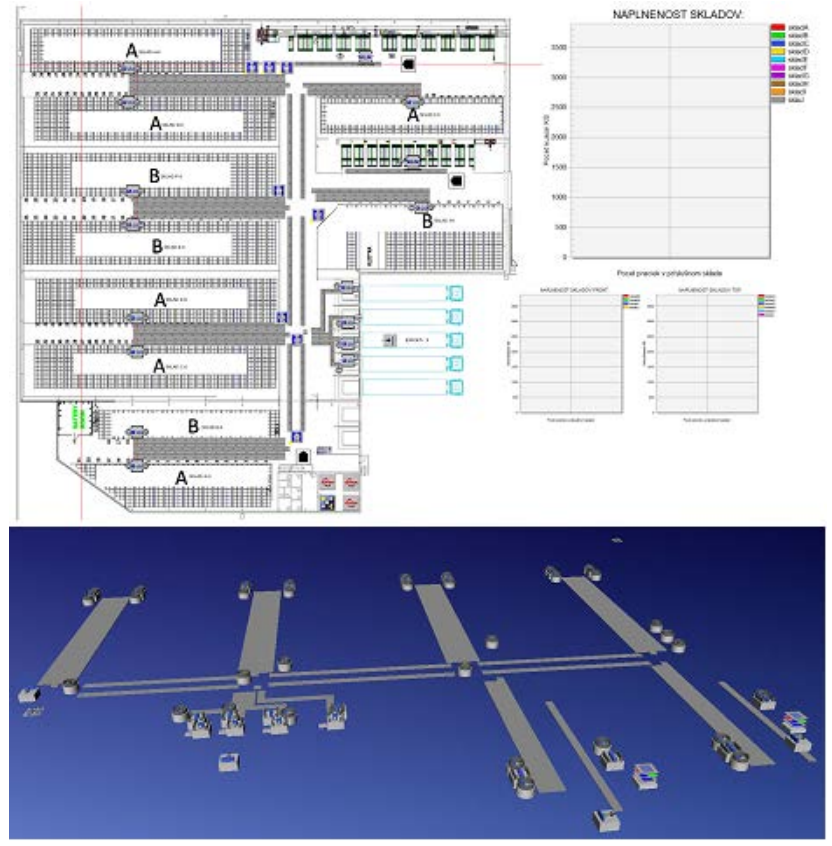

Figure 5. Simplified 2D and 3D storage model

Storage was done in the program with methods of programmable commands. Figure 4 shows 2D and 3D simplified model of storage, whose main task is to load products from conveyor belts and put them into the nearest free space for storage of the selected product type. 
For compiled simulation it was necessary to prepare the order for fulfillment warehouses, while in the program is secured continuous export. The nature of the command lies in the fact that if the road to the put-away is full, the truck is looking for more accessible warehouse in which they may execute the order. If one does not meet the condition, the truck remains on the one path that circles unless there is a specific condition, which is in the order programmed.

Simplified storage model:

Figure 5 shows 2D and 3D simplified model of enterprise storage process, whose main task is to load products from conveyor belts and put them into the nearest free space for storage of selected product type. Methods are set so to ensure smooth storage and removal from storage but also fluent export.

Report during the three-day simulation is shown in Figure 6.

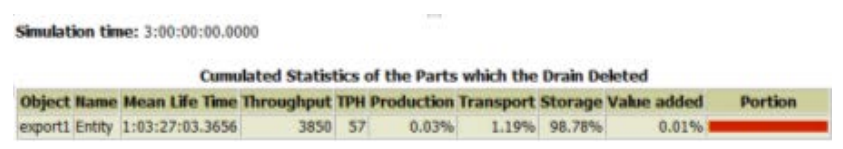

Figure 6. Software output generated after 3 days

From report average time of product spent from receipt trucks to export, the number how many pieces are exported, export per hour production time, transport time, storage time, added value and graph the total use of time can be revealed.

\section{Conclusion}

The paper aimed to highlight the practical use of Plant Simulation in industry and service complex object in a limited interface. Since today trend of information technology is progressing, it is essential that every major enterprise use digital planning methods, respectively changes realization in the current state.

By use of simulation:

- Company bottlenecks are discovered

- Time to prepare project is reduced

- Time for changes reduced

- Material flow planned

- Export of plans

\section{Acknowledgement}

This article was created by implementation of the grant projects KEGA 004TUKE-4/2013 Intensification of modeling in teaching II. and III. degree in the field of study 5.2.52 Industrial Engineering.

\section{References}

[1] MILlER, A., ŠIMON, M., JANUŠKA, M. Case Study: Optimizing of capacity utilization of machines in the production process variants. In Proceedings of The 22nd International Business Information Management Association Conference. Rome: International Business Information Management Association (IBIMA), 2013. s. 1513-1519.

[2] MILlER, A., KLEINOVÁ, J., ŠIMON, M. Proposal for evaluating variants of inter-company transport in business networks. In Innovation and Sustainable Economic Competitive Advantage. Istanbul: International Business Information Management Association (IBIMA), 2012. s. 2785-2792.

[3] POÓR, P., KUCHTOVÁ, N. Expert System - Methodology for Facility Management Deployment in Small or Medium Enterprise. In Proceedings of The 22nd International Business Information Management Association Conference. Neuveden: International Business Information Management Association (IBIMA), 2013. s. 1520-1526. 